\title{
Ion beam analysis, corrosion resistance and nanomechanical properties of TiAICN/CNx multilayer grown by reactive magnetron sputtering
}

B. Alemon, M. Flores, C. Canto, E. Andrade, O.G. de Lucio, M.F. Rocha and Esteban Broitman

\author{
Linköping University Post Print
}

\section{Tweet}

N.B.: When citing this work, cite the original article.

Original Publication:

B. Alemon, M. Flores, C. Canto, E. Andrade, O.G. de Lucio, M.F. Rocha and Esteban Broitman, Ion beam analysis, corrosion resistance and nanomechanical properties of TiAlCN/CNx multilayer grown by reactive magnetron sputtering, 2014, Nuclear Instruments and Methods in Physics Research Section B: Beam Interactions with Materials and Atoms, (331), 134-139.

http://dx.doi.org/10.1016/j.nimb.2013.12.040

Copyright: Elsevier http://www.elsevier.com/

Postprint available at: Linköping University Electronic Press http://urn.kb.se/resolve?urn=urn:nbn:se:liu:diva-109371 


\title{
Ion beam analysis, corrosion resistance and nanomechanical properties of TiAICN/CN $\mathrm{N}_{x}$ multilayer grown by reactive magnetron sputtering
}

\author{
B. Alemón ${ }^{1}$, M. Flores ${ }^{1}$, C. Canto ${ }^{2}$, E. Andrade ${ }^{2}$, O.G. de Lucio ${ }^{2}$, M.F.Rocha ${ }^{3}$, E. \\ Broitman ${ }^{4}$.
}

1. Departamento de Ingeniería de Proyectos, CUCEI, Universidad de Guadalajara, J. Guadalupe Zuno 48, Los Belenes, Zapopan Jal., 45101, México

2. Instituto de Física, UNAM, Avenida de la Investigación S/N, Coyoacán, México

D. F., 04510, México.

3. ESIME-Z, Instituto Politécnico Nacional, ALM Zacatenco, 07738 México D. F., México

4. Thin Films Physics Division, IFM, Linköping University, Sweden, SE-58183 Linköping.

\begin{abstract}
:
A novel TiAICN $/ \mathrm{CN}_{x}$ multilayer coating, consisting of nine TiAICN/CN $\mathrm{N}_{\mathrm{x}}$ periods with a top layer $0.5 \mu \mathrm{m}$ of $\mathrm{CN}_{\mathrm{x}}$, was designed to enhance the corrosion resistance of CoCrMo biomedical alloy. The multilayers were deposited by $d c$ and $R F$ reactive magnetron sputtering from $\mathrm{Ti}_{0.5} \mathrm{Al}_{0.5}$ and $\mathrm{C}$ targets respectively in a $\mathrm{N}_{2} / \mathrm{Ar}$ plasma. The corrosion resistance and mechanical properties of the multilayer coatings were analyzed and compared to CoCrMo bulk alloy. Ion beam analysis (IBA) and X-ray diffraction tests were used to measure the element composition profiles and crystalline structure of the films. Corrosion resistance was evaluated by means of potentiodynamic polarization measurements using simulated body fluid (SBF) at typical body temperature and the nanomechanical properties of the multilayer evaluated by nanoindentation tests were analyzed and compared to CoCrMo bulk alloy. It was found that the multilayer hardness and the elastic recovery are higher than the substrate of CoCrMo. Furthermore the coated substrate shows a better general corrosion resistance than that of the CoCrMo alloy alone with no observation of pitting corrosion.
\end{abstract}

Key words: Ion beam analysis; corrosion; $\mathrm{TiAICN} / \mathrm{CN}_{\mathrm{x}}$ multilayer coating; nanoindentation. 


\section{Introduction}

Nowadays, CoCrMo alloys are used in prosthetics manufacturing for both hip and knee implants due to their biocompatibility and also due to superior mechanical properties and high wear resistance than other biocompatible materials [1]. However disadvantages during real use have been reported, including lower resistance to corrosion and decreased biocompatibility due to the release of metal ions in the body compared to $\mathrm{Ti}_{6} \mathrm{Al}_{4} \mathrm{~V}$ [1-4]. One way to improve the properties of CoCrMo alloys without losing their mechanical properties is to apply coatings by physical vapor deposition (PVD) methods [5-7].

It has been shown that nitride coatings, such as titanium nitride (TiN) [8] and titanium nitride-aluminum nitride TiN/AIN [9], and tetrahedral amorphus carbon films [10], deposited over CoCrMo alloy substrates are biocompatible and they have good tribological properties that improve the prosthesis material both in performance as well as length of useful life [11, 12]. Additionally, Broitman et al. have found that $\mathrm{CNx}$ films layered on orthopedic substrates such as $\mathrm{ZrO}_{2}$ present a low coefficient of friction (COF) bellow 0.18 when they were evaluated against ultra-high molecular weight polyethylene (UHMWPE) in the presence of human serum lubricants. Their research has further demonstrated that the $\mathrm{CN}_{\mathrm{x}}$ films possess the potential to generate low wear conditions for these polymer [13]. Other investigations have shown that multilayers improve the corrosion and wear resistance of the substrate $[14,15]$. However the use of multilayer coatings for biomedical applications has attained relatively low attention.

This work reports studies of a novel TiAICN/CN $/ N_{x}$ multilayer deposited on CoCrMo biomedical alloy by reactive magnetron sputtering with the purpose of enhancing corrosion resistance of the substrate.

The quality of the coatings depends on their elemental composition and it is related to the PVD deposition parameters. For an optimization of the deposition parameters it is necessary to know the absolute content of $\mathrm{Ti}, \mathrm{Al}, \mathrm{N}$ and $\mathrm{C}$. The analysis of the layers with $\mathrm{N}$ and $\mathrm{C}$ with RBS suffers in many cases from the difficulty to quantify these elements because of the relatively small sensitivity compare to heavy elements. A combination of Rutherford backscattering (RBS) with Nuclear Reaction Analysis (NRA) techniques allowed a precise determination of the $\mathrm{Ti}, \mathrm{Al}, \mathrm{N}$ and $\mathrm{C}$ elements profile without ambiguity. The NRA was performed with a $1300 \mathrm{keV}$ deuterium beam and the RBS with a $2000 \mathrm{keV}{ }^{4} \mathrm{He}$ beam. The hardness and reduced 
Young's modulus were investigated by nanoindentation technique and the corrosion resistance in simulated body fluid (SBF) was studied by potentiodynamic polarizations tests.

\section{Experimental details}

Discs of low carbon CoCrMo alloys (ASTM F 1537, $C(0.04 \%)$, $\mathrm{Mo}(0.81 \%), \operatorname{Cr}(27.58 \%), \mathrm{Co}(64.99 \%)$ of $31.75 \mathrm{~mm}$ in diameter and $6 \mathrm{~mm}$ thick were ground flat with sandpaper of 240,400,600, 1200 grades and subsequently polished with diamond paste until a roughness of $\mathrm{Ra}$ of $0.03 \mu \mathrm{m}$ (measured with a Dektak 150 profilometer) was achieved. Before the deposition, the substrates were ultrasonic cleaned for fifteen minutes in acetone and then in isopropyl alcohol and dried with clean air. The multilayers were deposited by DC and RF reactive magnetron sputtering from TiAl and $C$ targets respectively in $\mathrm{N}_{2} / A$ r plasma. The substrate rotates in the process at a distance of $60 \mathrm{~mm}$ from the targets. A pure titanium target $(99 \%)$, a high purity (99.99\%) graphite target and a high purity (99.95\%) $\mathrm{Ti}_{0.5} \mathrm{Al}_{0.5}$ target were used during the experiments. Fig. 1 shows a schematic diagram of the arrangement of the targets in the vacuum chamber. The multilayer nominal composition consists of 9 periods of TiAICN (180nm thick) alternating with $\mathrm{CN}_{\mathrm{x}}(60 \mathrm{~nm}$ thick) layers. The first deposit on the substrate was a titanium layer (100nm thick) to promote adhesion of the multilayers deposit. Also a $\mathrm{CN}_{\mathrm{x}}$ layer on the top of the coatings (480nm thick) was deposited. Fig. 2 shows a schematic diagram of the multilayer coating. For statistical purposes, five similar coatings were prepared for these studies.

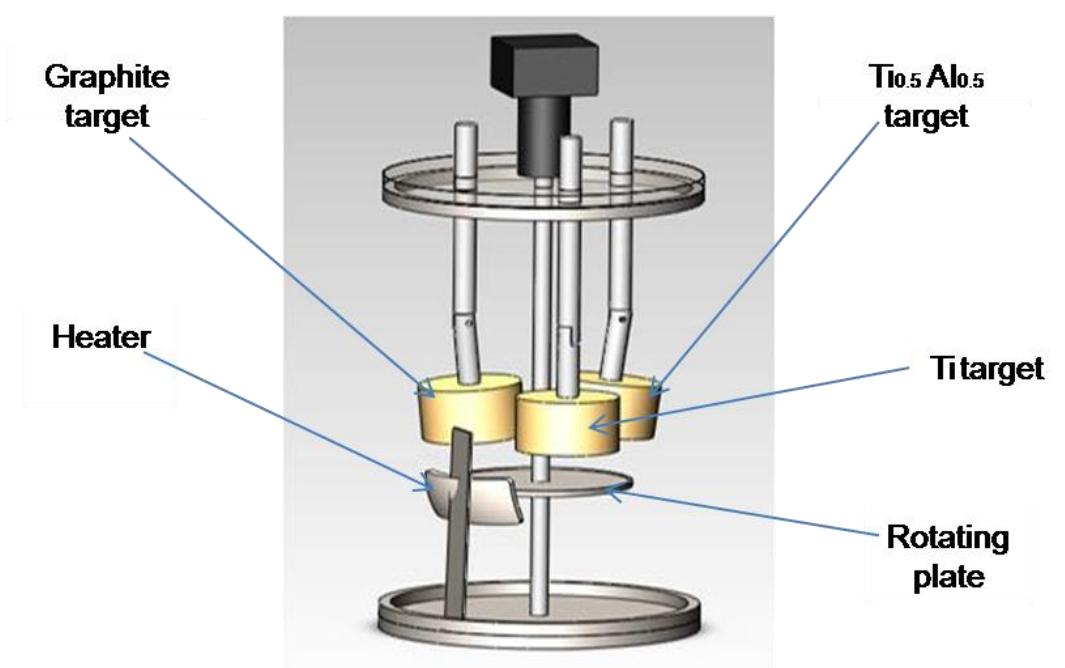

Fig.1. PVD targets arrangement for the sputtering process deposition of the TiAICN/CN multilayer coating 


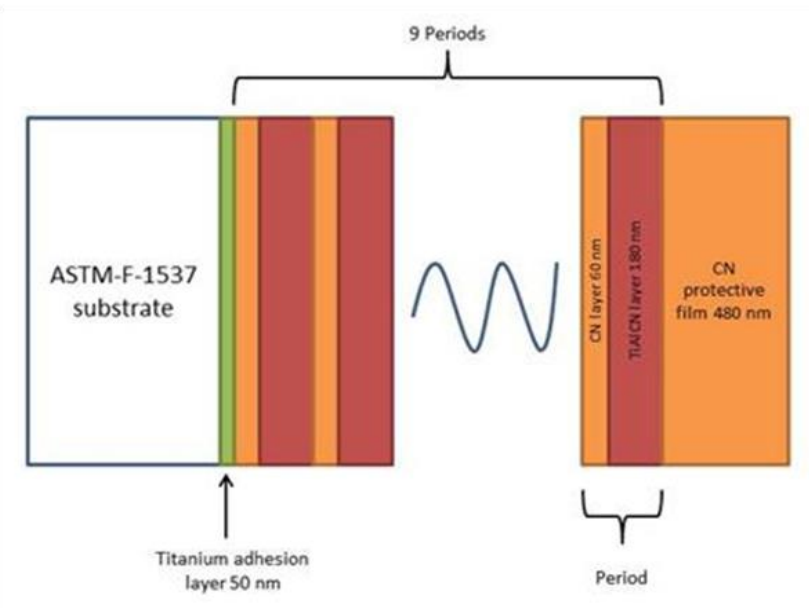

Fig.2. Schematic representation of the experimental design of the multilayer film composition and film thickness. The total coating thickness ranges from 2.7 to $3 \mu \mathrm{m}$.

The initial vacuum pressure of the deposition chamber was $\sim 3.9 \times 10^{-4} \mathrm{~Pa}\left(3 \times 10^{-6}\right.$ Torr). The substrates were preheated at $125^{\circ} \mathrm{C}$ for $30 \mathrm{~min}$ and sputter cleaned using radio frequency (RF) applied to the substrates at argon pressure of $\sim 0.26 \mathrm{~Pa}(2 \mathrm{~m}$ Torr) with a power of 40 watts for 20 minutes.

Multilayer TiAICN $/ \mathrm{CN}_{x}$ was grown at a temperature $\sim 125^{\circ} \mathrm{C}$. The first titanium layer on the substrate was deposited by sputtering the Ti target in an Ar discharge at a pressure of $.26 \mathrm{~Pa}$ (2mTorr) and DC constant current of $0.6 \mathrm{~A}$. The TiAICN layers were obtained by codeposition of TiAl using a DC source with a constant current of $0.6 \mathrm{~A}$ and graphite with the AC power source (RF) at a power density of $10 \mathrm{~W} / \mathrm{cm}^{2}$. The $\mathrm{CN}$ interlayer and top layer was obtained with RF power of $200 \mathrm{~W}$. During the deposition of the multilayers a bias voltage of $-40 \mathrm{~V}$ was applied to the substrate. The flow rate of $\mathrm{Ar} / \mathrm{N}_{2}$ was changed during the deposition process and it was $60 / 40$ for TiAICN and 43/57 for CN. Each layer was deposited without turning off the plasma in order to obtain a gradual change between the layers.

A vertical single ended 5.5 MV Van de Graff accelerator was used to apply a combination of the RBS technique with a $2000 \mathrm{keV}{ }^{4} \mathrm{He}$ beam and the NRA technique with a $1300 \mathrm{keV}$ deuterium beam. Each sample was bombarded at the same beam spot at normal beam incidence. A surface barrier detector (SBD), located $150^{\circ}$ degree with standard electronic, recorded the particle energy spectra.

For the NRA experiments the deuterium beam current was relative high (about 100 na) and the SBD had in front a 15 microns kapton film to absorb the elastically backscattered deuterium from the target nuclei in order to measure only the high energy NR particles from the $(d, p)$ and $(d, \alpha)$ nuclear reactions produced by the 
bombardment on $\mathrm{C}$ and $\mathrm{N}$ nuclei. The NR cross sections of these nuclei are two or three orders of magnitude smaller compare to the RBS cross sections, producing a low particle counting rate. A big solid angle was used with this SBD in order to measure more efficiently the NR particles and to obtain a NRA spectrum in a short time with a good statistics.

The crystal structure of the low CoCrMo alloy substrate and multilayer coating was analyzed using $\mathrm{Cu} \mathrm{Ka}(\lambda=0.15406)$ in Siemens D500 X-Ray diffractometer. A conventional $\theta / 2 \theta$ Bragg-Brentano symmetric geometry was used, from $20^{\circ}$ to $100^{\circ}$, with a step size of $0.03^{\circ}$ and a time step of $1 \mathrm{~s}$.

The mechanical properties of TiAICN/CN and the substrate were evaluated by nanoindentation experiments in a TI 950 triboindenter $^{\mathrm{TM}}$ (Hysitron). Hardness $(H)$ and reduced Young's modulus $\left(E_{r}\right)$ were measured using a Berkovich diamond indenter. The values were calculated according to the method by Oliver and Pharr [16]. In order to avoid the combined effect of the coating and the substrate, penetration displacement was slightly less than $10 \%$ of the total coating thickness. In all depthsensing tests a total of 10 indents were averaged to determine the mean $\mathrm{H}, \mathrm{E}_{\mathrm{r}}$ and their standard deviation. The displacements were continuously recorded during the indentations. The penetration displacement of the indenter at maximum load $\left(\mathrm{h}_{\max }\right)$ and the final displacement $h_{f}$ recorded in the unloading curve were used to determine the percentage of elastic recovery $(\% R)[17]$.

$$
\% R=\left(\frac{h_{\max }-h_{f}}{h_{\max }}\right)(100)
$$

The electrochemical study was carried out using a potentiostat Gamry reference 600. The SBF prepared according the method of Kokubo et al. [18] was used as electrolyte in the measurements. The test was performed using a three electrode cell. A saturated calomel electrode (SCE) was used as the reference electrode, a flat platinum wire as counter electrode and the sample as working electrode. The temperature of the electrolyte is controlled by a recirculation of water at $36.5^{\circ} \mathrm{C}+/-1.5^{\circ} \mathrm{C}$. The sample was immersed in $50 \mathrm{ml}$ SBF solution with $\sim 1 \mathrm{~cm}^{2}$ exposed area.

The corrosion resistance of the multilayer was evaluated using potentialcurrent curves obtained by potentiodynamic polarization. All the potentials reported 
here are referred to the SCE. The corrosion current density $i_{\text {corr }}$ was estimated by linear fit and Tafel extrapolation to the anodic part of the polarization curve.

\section{Results and discussion}

\section{1 lon beam results}

Fig. 3 shows a RBS spectrum from a $2000 \mathrm{keV}{ }^{4} \mathrm{He}$ bombardment of one of the multilayer TiAICN/CN $\mathrm{N}_{x}$ coatings while Fig. 4 shows a portion of the NRA spectrum obtained with a deuteron beam with energy of $1300 \mathrm{keV}$ from the irradiation on the same spot in the sample. The solid line represents the SIMNRA [19] simulation of the spectra used to obtain the atomic profiles shown in Fig. 5 of the four elements in the coating. RBS cross sections for the $\mathrm{Ti}$ and $\mathrm{Al}$ and non RBS cross sections for elastic backscattering $\mathrm{N}$ and $\mathrm{C}$ were used to simulate the spectrum. The difficulty to quantify $\mathrm{N}$ and $\mathrm{C}$ from the RBS spectrum due to its small sensitivity compare to heavy elements was resolved by the simultaneous simulation of the NRA and RBS spectra. Some of the NR peaks identified in the NRA spectrum used for the simulation were: ${ }^{14} \mathrm{~N}\left(\mathrm{~d}, \alpha_{1}\right){ }^{12} \mathrm{C}[20],{ }^{14} \mathrm{~N}\left(\mathrm{~d}, \mathrm{p}_{3}\right){ }^{15} \mathrm{~N}[21],{ }^{14} \mathrm{~N}\left(\mathrm{~d}, \mathrm{\alpha}_{0}\right){ }^{12} \mathrm{C}$ [22], and ${ }^{12} \mathrm{C}\left(\mathrm{d}, \mathrm{p}_{0}\right){ }^{13} \mathrm{C}$ [23]. The numbers inside the parenthesis are the reference of the NR cross sections from the IBANDL (ion beam analysis data library) data base.

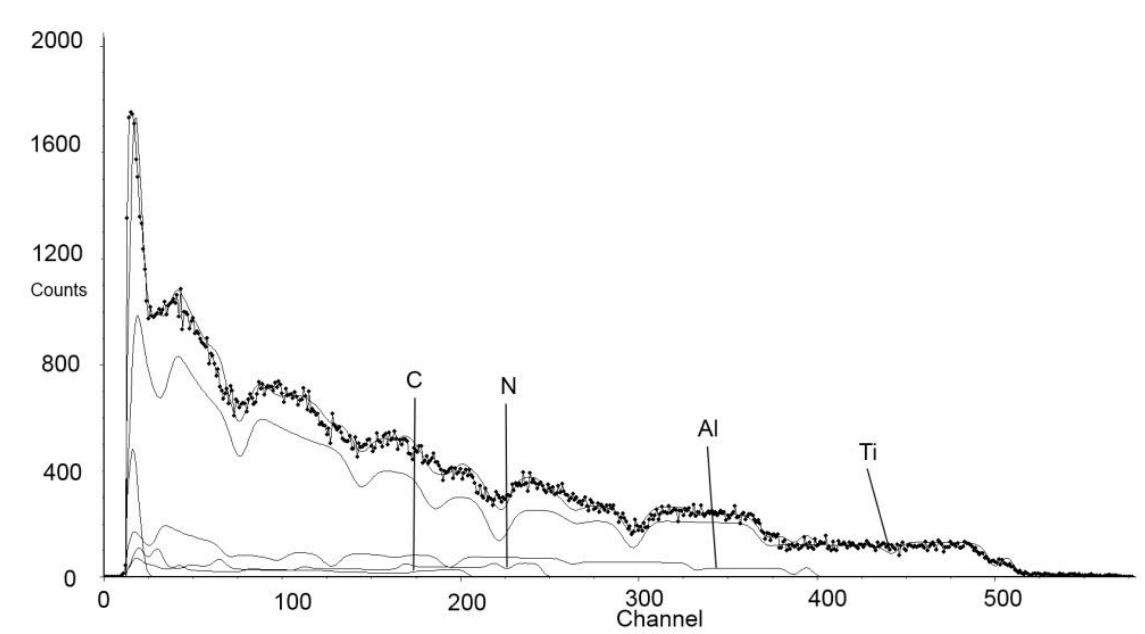

Fig.3. RBS spectrum from a $2000 \mathrm{keV}{ }^{4} \mathrm{He}$ bombardment of one of the multilayer TiAICN/CN $\mathrm{CN}_{\mathrm{x}}$ coatings on CoCrMo substrate. The multilayer structure of the coating can be observed due to the ${ }^{4} \mathrm{He}$ good energy depth resolution. The solid line represents the SIMNRA simulation of the spectrum. The Ti, $\mathrm{Al}, \mathrm{N}$ and $\mathrm{C}$ partial contributions in the simulation are also plotted. 


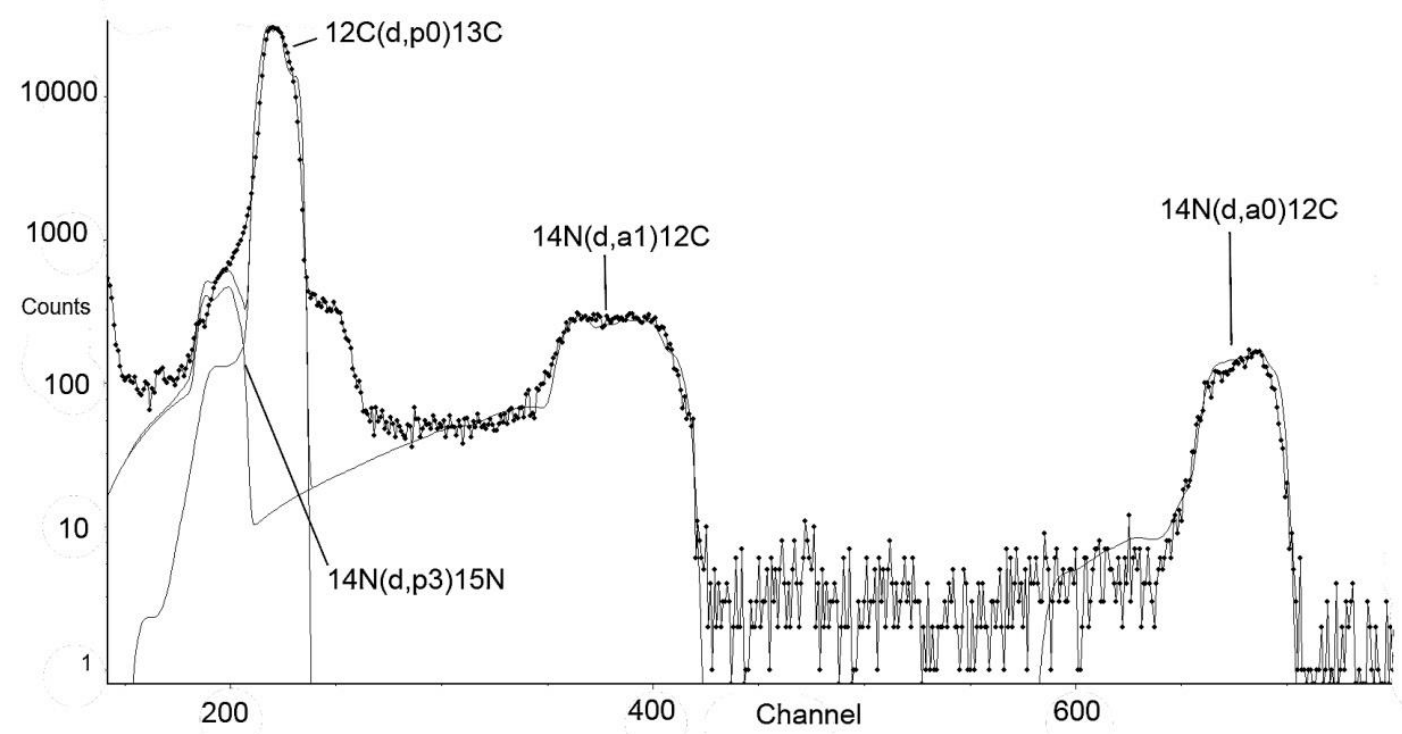

Fig.4. Segment of the NRA spectrum from the $1300 \mathrm{keV}$ deuterium bombardment of the coating in the same beam spot of the RBS. The solid line represents the SIMNRA simulation of the spectrum.
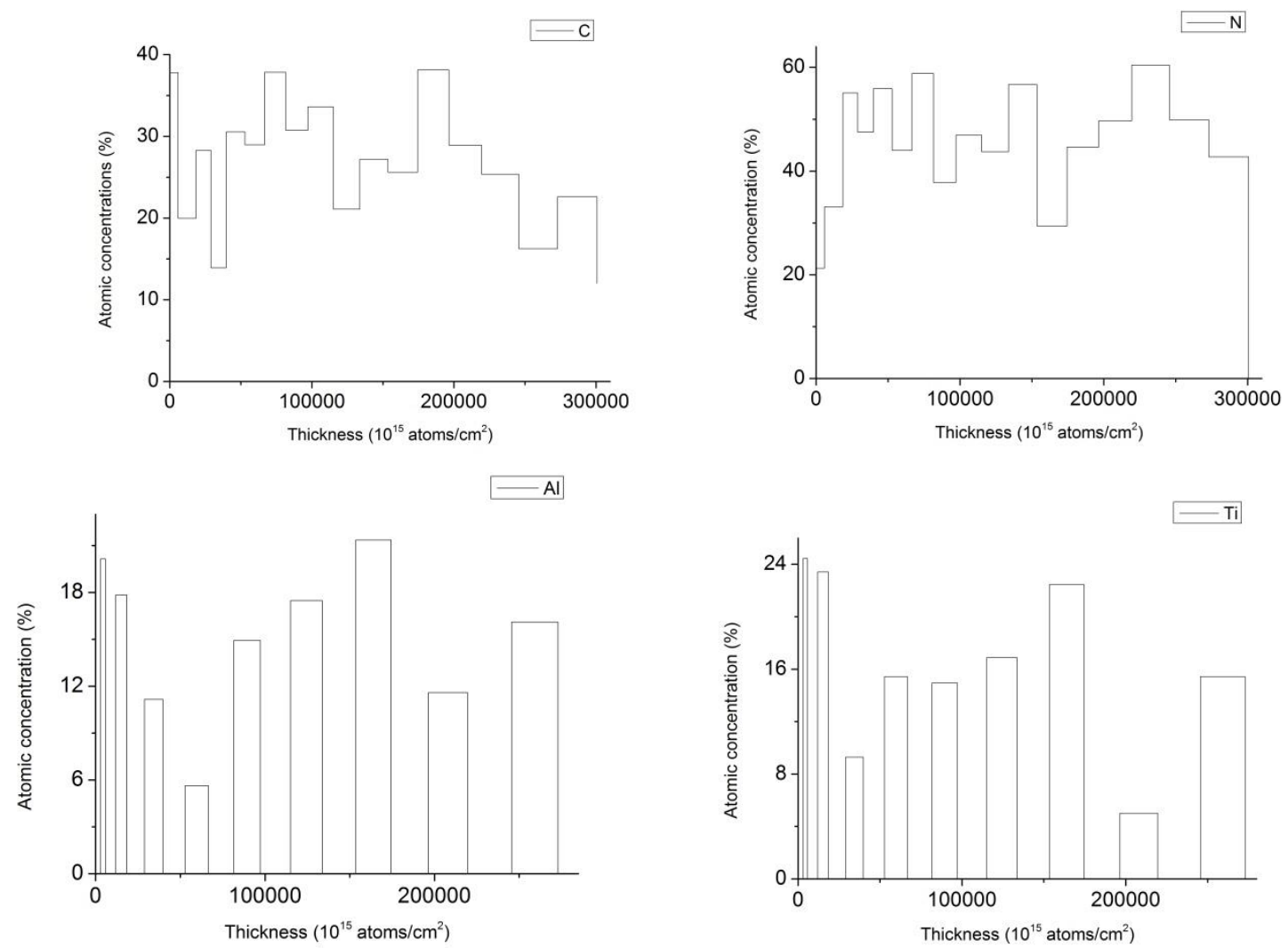

Fig.5. The Ti, Al, N and C atomic (\%) profiles of the TiAINC/CN ${ }_{x}$ obtained from the SIMNRA simulation of the RBS and NRA spectrum from Fig. 4 and Fig. 5 
In Fig. 5, the elemental profile for $\mathrm{C}, \mathrm{N}, \mathrm{Al}$ and $\mathrm{Ti}$ are shown for the whole film. $\mathrm{Ti}$ and $\mathrm{Al}$ are absent in some part of the depth profile and this is a consequence of the multilayer design. It is also shown in Fig 5 , that there are clear gaps between the layers with aluminum and those without it, which demonstrate no diffusion of the heavy elements $\mathrm{Ti}$ and $\mathrm{Al}$ in $\mathrm{CN}$ layers.

\subsection{XRD results}

Fig. 6 shows the diffactogram of a TiAICN/CN multilayer coating deposited onto CoCrMo compared to a CoCrMo diffraction pattern. Both XRD plots matches together but the intensity of the coated CoCrMo substrate peaks are attenuated by $60-70 \%$ due to the presence of the multilayer coating. The XRD did not reveal the presence of extra peaks indicating that the multilayer has an amorphous structure, as we expected because of the low substrate temperature used during the deposition process [17].

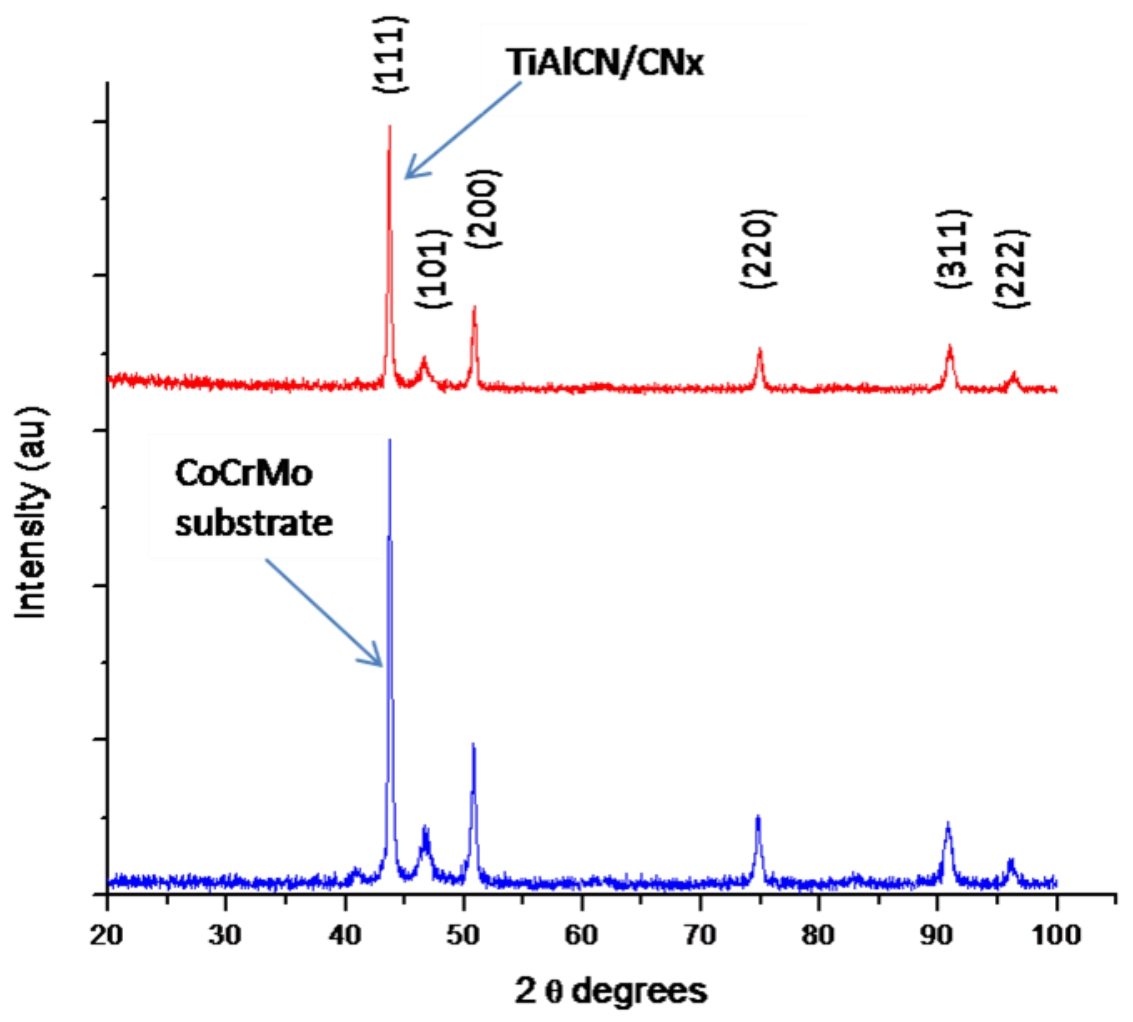

Fig.6. XRD diffraction patterns from the CoCrMo coated with the TiAICN/CNx multilayer and CoCrMo substrate

\subsection{Nanoindentation results}


Fig. 7 compares the load displacement curves from nanoindentation measurements for the TiAICN/CN ${ }_{x}$ multilayer coating and the uncoated CoCrMo substrate. Table 1 shows hardness $(H)$ and reduced Young's modulus $\left(E_{r}\right)$ calculated according Oliver-Pharr approach [16]. The multilayer is slightly harder than the substrate but its $E_{r}$ is $50 \%$ lower than substrate. The percentage of elastic recovery $(\% \mathrm{R})$ of the multilayer resulted $68 \%, 2.6$ times higher than the \%R of the substrate due to the thick top layer of $\mathrm{CN}_{\mathrm{x}}$ on the multilayer coating, as it has previously shown by Broitman, et al. [17]. We conclude that our design of the multilayers deposited onto the CoCrMo alloys improves the mechanical properties of the substrates and will probably increase their life time [24].

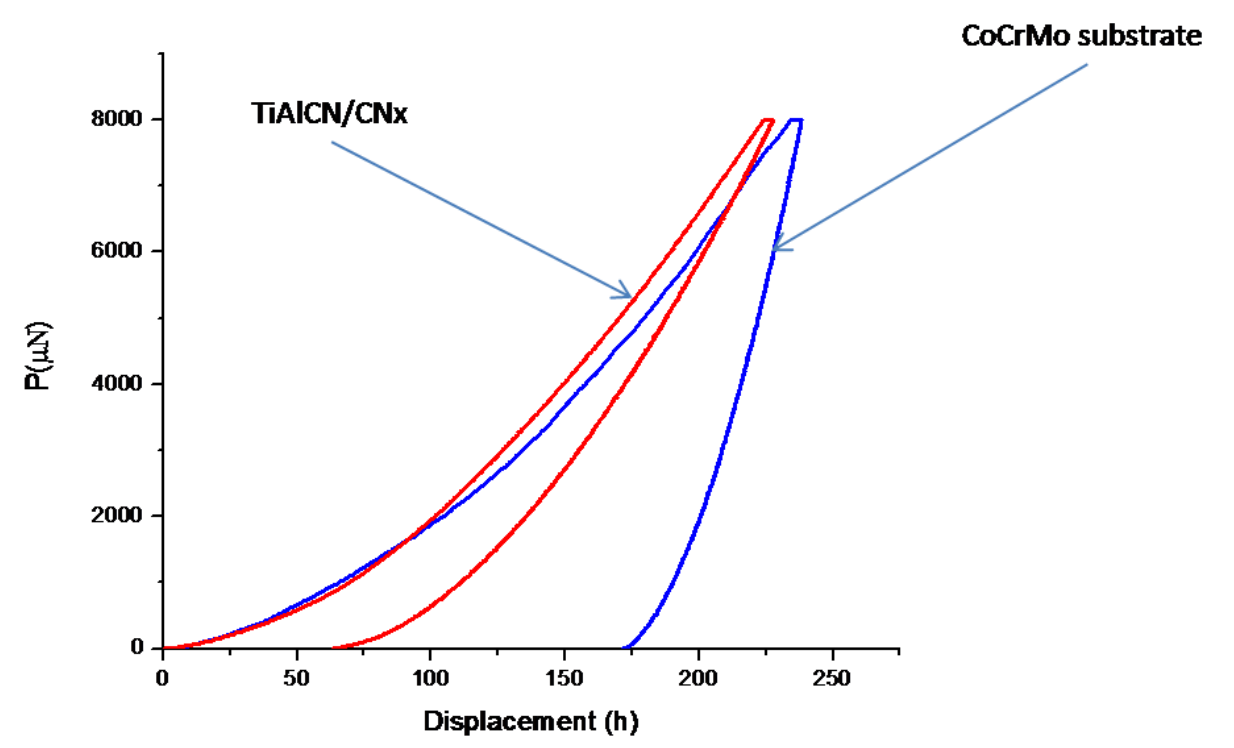

Fig.7. Nanoindentation load displacement curves from TiAICN/CNx multilayer coating in comparison with CoCrMo curves

Table1. Values of Hardness, $\mathrm{Er}$ and \% elastic recovery of CoCrMo substrate uncoated and coated with TiAICN/CNx multilayer

\begin{tabular}{|cccc|}
\hline & $\begin{array}{c}\text { Hardness } \\
(\mathrm{Gpa})\end{array}$ & $\begin{array}{c}\text { Reduced Young's } \\
\text { Modulus(Gpa) }\end{array}$ & $\begin{array}{c}\text { Elastic Recovery } \\
\%\end{array}$ \\
$\begin{array}{c}\text { CoCrMo } \\
\text { Substrate in SBF } \\
\text { TiAICN/CN }\end{array}$ & $8.69+/-0.3$ & $186.9+/-4.6$ & $26.2+/-4.6$ \\
& $10.8+/-0.9$ & $86.3+/-3.2$ & $68.2+/-2.2$ \\
\hline
\end{tabular}




\subsection{Corrosion resistance results}

In comparison to the uncoated substrate, the potentiodynamic polarization tests results indicated a better behavior for corrosion in SBF of the substrate coated with TiAICN/CN $\mathrm{CN}_{\mathrm{x}}$ multilayer. Fig. 8 shows that the pitting corrosion potential of the CoCrMo starts at $\sim 0.44 \mathrm{~V}$. On the other hand, at the same potential, there is no change in the anodic part of the potentiodynamic curve of the TiAICN/CN $\mathrm{N}_{\mathrm{x}}$ indicating that there is not pitting corrosion for the multilayer coated substrate in the studied interval. In Table 2, the value of $\mathrm{E}_{\text {corr }}$ of the uncoated CoCrMo alloy is more negative than the TiAICN/CN $/ N_{x}$, which indicates that the coated sample has a lower tendency to be corroded. The $I_{\text {corr }}$ value of the uncoated CoCrMo obtained by Tafel extrapolation is three times higher than the multilayer coated CoCrMo. We can then conclude that the multilayer coating provides a higher corrosion resistance to general and localized corrosion.

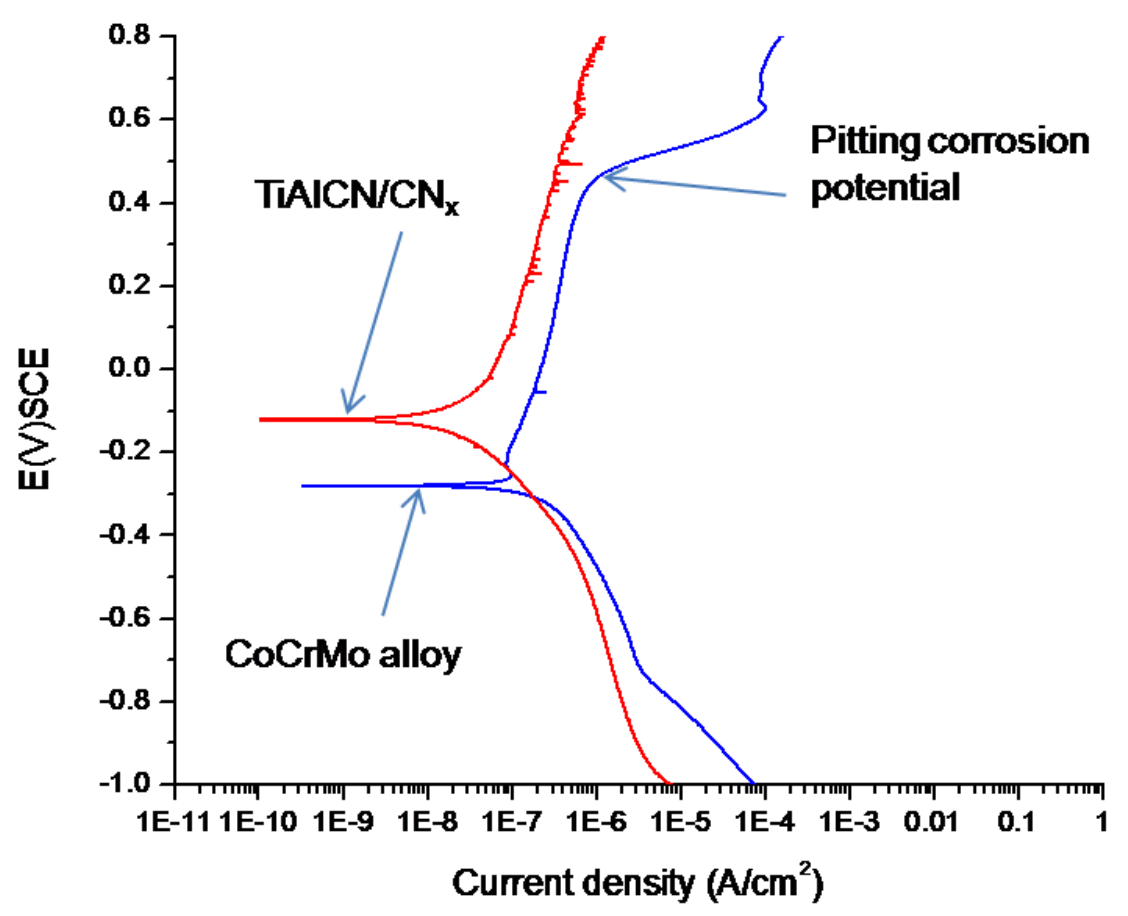

Fig.8. Potentiodynamic polarization curves for the multilayer coated and uncoated surfaces of CoCrMo. 
Table 2. Values of Ecorr, Icorr and pitting corrosion of CoCrMo substrate uncoated and coated with $\mathrm{TiAICN} / \mathrm{CN}_{\mathrm{x}}$ multilayer

\begin{tabular}{|cccc|}
\hline $\begin{array}{c}\text { CoCrMo } \\
\text { Substrate in SBF } \\
\text { TiAICN/CN }\end{array}$ & -0.28 & $7.24 \times 10^{-8}$ & $\begin{array}{c}\mathrm{E}_{\text {portting corrosion }}(\text { Volts }) \\
0.44\end{array}$ \\
\hline & -0.12 & $2.14 \times 10^{-8}$ & $\begin{array}{c}\text { None in the } \\
\text { potential } \\
\text { interval }\end{array}$ \\
\hline
\end{tabular}

\section{Conclusions}

A novel multilayer film of TiAICN/CN was designed and deposited on a CoCrMo substrate by reactive magnetron sputtering technique.

A couple of ion beam analysis techniques (RBS and NRA) were used to analyze the elemental profile of the film, and the results were applied to correlate the deposition parameters with the composition and thickness of every layer of the multilayer coating. The combination of both techniques and the simultaneous simulation of the RBS and NRA spectra allow us to determine the Ti, Al, N and C elements profile with reduced ambiguity.

XRD analysis results have confirmed that the multilayer coatings are amorphous.

Nanoindentation experiments strongly suggest that the $\mathrm{TiAICN} / \mathrm{CN}_{\mathrm{x}}$ multilayer coating has improved the mechanical properties of the uncoated substrate, with higher hardness and elastic recovery.

Potentiodynamic polarization tests indicated a better behavior for corrosion of the multilayer coating in SBF.

It can be concluded that the CoCrMo substrate coated with the designed TiAICN/CN $\mathrm{C}_{\mathrm{x}}$ multilayer provides to the substrates improved mechanical properties and increased protection against pitting and general corrosion.

\section{Acknowledgements}

The authors acknowledge the CONACYT partially support, project number 49172 and by the UNAM DGAPA project IN103312. E. Broitman acknowledges the Swedish Government Strategic Research Area Grant in Materials Science. The 
authors acknowledge the work and help of M. en C. Eustacio Pérez Zavala and Arcadio Huerta for technical assistance.

\section{References}

[1] Masao Sumita, S.H.T., Durability of metallic implant materials. Biomaterials Engineering and Processing Series. Vol. 1. 2004, Singapore: World Scientific Publishing Co. Pte. Ltd. 350.

[2] A. Sargeant, and T. Goswami, Mater Des 28(1) (2007) 155-171.

[3] X. Mao, A.A. Wong, and R.W. Crawford, Med J Aust 194(12)(2011) 649-51.

[4] S.B. Goodman, et al., J Biomed Mater Res A 90A(2)(2009) 603-618.

[5] H. Holleck, V. Schier, Surf Coat Technol, 76-77 [Part 1(0): 328-336].

[6] G. Thorwarth, et al., Acta Biomater, 6(6)(2010) 2335-2341.

[7] J.A. Ortega-Saenz, M. Alvarez-Vera, M.A.L. Hernandez-Rodriguez, Wear, 301 (12)(2013) 234-242.

[8] A. Wisbey, P.J. Gregson, M. Tuke, Biomaterials, 8(6)(1987) 477-480.

[9] J.R. Goldberg, J.L. Gilbert, Biomaterials, 25(5)(2004) 851-864.

[10] V.M. Tiainen, Diamond Relat Mater, 10(2)(2001) 153-160.

[11] Disegi JA, Kennedy RL, Pilliar L. Cobalt-Base alloys for biomedical applications: American Society for Testing \& Materials; 1999.

[12] Karl Dahm, Peter Dearnley, Mechanical response of coated implant alloys. In M.P.C.M.T.P.E.T.H.C.C.G.D.A.A.L.Y.B.L.F. D. Dowson and J.M. Georges, editors. Tribology Series, 2000, Elsevier. p.155-161.

[13] E. Broitman et al., Diam Relat Mater 9(12)(2000) 1984-1991.

[14] M. Flores, et al., Surf Coat Technol, 200(5-6) (2005) 1315-1319.

[15] H.A. Jehn, Surf Coat Technol, 131(1-3) (2000) 433-440.

[16] W.C. Oliver, and G.M. Pharr, J Mater Res 7(06)(1992) 1564-1583.

[17] E. Broitman, et al., Wear 248(1-2)(2001) 55-64.

[18] T. Kokubo, H. Takadama, Biomaterials, 27(15) (2006) 2907-2915.

[19] M. Mayer, SIMNRA, a simulation program for the analysis of NRA, RBS and

ERDA. AIP Conf Proc 475(1)(1999) 541-544.

[20] G. Amsel, D. David, Rev Phys Appl 4 (1969), 383 [data retrieved from the IBANDL database, IAEA, 2013 http://www-nds.iaea.org/ibandl/.

[21] S. Pelegrino, Nucl Instrum Method B 219 (2004) 140, [data retrieved from the IBANDL database, IAEA, 2013 at http://www-nds.iaea.org/ibandl/].

[22] S. Pellegrino et al. NIM B 219-220 (2004) 140, [data retrieved from the IBANDL database, IAEA, 2013 at http://www-nds.iaea.org/ibandl/].

[23] M.Kokkoris et al., Nucl. Instr. and Meth. B249 (2006) 77, [data retrieved from the IBANDL database, IAEA, 2013 at http://www-nds.iaea.org/ibandl/].

[24] C.A. Charitidis, Int J Refract Met Hard Mater 28(1) (2010) 51-70. 